\title{
A STUDY CORRELATING POSITIVITY OF ACID FAST BACILLI (AFB) IN CYTOLOGIC ASPIRATES SHOWING GRANULOMATOUS INFLAMMATION
}

\author{
Asha Borah', Bobby Duarah ${ }^{2}$
}

${ }^{1}$ Assistant Professor, Department of Pathology, Assam Medical College, Dibrugarh. ${ }^{2}$ Associate Professor, Department of Pathology, Assam Medical College, Dibrugarh.

\section{ABSTRACT}

\section{BACKGROUND}

Tuberculosis is the archetype of granulomatous diseases and understanding this disease is very important as its incidence is high in India.

\section{AIM}

In the present study, an attempt has been made to evaluate the efficiency of AFB staining in diagnosing mycobacterial disease and to correlate AFB positivity with the cytomorphological parameters.

\section{MATERIAL AND METHODS}

Patients of all age groups were included who presented with an external swelling, which on cytological examination revealed a granulomatous picture (Typical and/or atypical). Air dried smears were made and stained by May Grunwald-Giemsa stain and ZiehlNeelsen stain respectively.

\section{RESULTS}

Out of 1000 cases attending the Cytology section of Pathology Department, 100 cases turned out to be granulomatous variety. Majority of the cases were of tubercular (89\%) origin and the rest (11\%) included the non-tubercular granulomatous lesions. Staining with standard Ziehl-Neelsen method showed AFB positivity in the tubercular lesions only. Overall, AFB positivity was 57.3\%; 60 (67.4\%) cases of epithelioid granuloma with necrosis seen; 14 (15.7\%) cases of epithelioid granuloma without necrosis seen; 15 (16.8\%) cases of necrosis without epithelioid granuloma seen. AFB positivity was highest in cases of necrosis without epithelioid granuloma, i.e. in $73.3 \%$ cases; $61.6 \%$ AFB positivity was seen in epithelioid granuloma with necrosis; $21.4 \%$ AFB positivity was seen in epithelioid granuloma without necrosis - least of all $p<0.001$ which is very highly significant; $74.5 \%$ cases showed bacillary count of grade $1+$.

\section{CONCLUSION}

Demonstration of tubercle bacilli in cytology aspirates by Ziehl-Neelsen staining is a simple and cost effective method to confirm a tubercular pathology. Overall, AFB positivity was $57.3 \%$, but it was highest (73.3\%) in cases showing necrosis without epithelioid granuloma where cytodiagnosis of tuberculosis is very difficult.

\section{KEYWORDS}

AFB, Granulomatous Inflammation, FNAC.

HOW TO CITE THIS ARTICLE: Borah A, Duarah B. A study correlating positivity of acid fast bacilli (AFB) in cytologic aspirates showing granulomatous inflammation. J. Evolution Med. Dent. Sci. 2016;5(51):3278-3282, DOI: 10.14260/jemds/2016/760

\section{INTRODUCTION}

In a country like India where tuberculosis is a rampant disease, early diagnosis and treatment is the approach to control this disease. There are 16 to 20 million cases of tuberculosis in the world. Annual incidence of tuberculosis (Both pulmonary and extra-pulmonary) is 8.2 million, $95 \%$ of which occur in developing countries. Microscopy is a very cost effective method to diagnose tuberculosis. In the recent years, fine needle aspiration cytology has been used as the first line of diagnostic step in making diagnosis of tubercular aspirates.

Financial or Other, Competing Interest: None.

Submission 05-05-2016, Peer Review 04-06-2016,

Acceptance 09-06-2016, Published 25-06-2016.

Corresponding Author:

Dr. Asha Borah,

Assistant Professor,

Department of Pathology

$1^{\text {st }}$ Floor Basic Science Building,

Assam Medical College \& Hospital,

Dibrugarh-786002, Assam.

E-mail: drashaborah@gmail.com

DOI: $10.14260 /$ jemds $/ 2016 / 760$
FNAC avoids the physical and psychological trauma occasionally encountered after open surgical biopsy. Cytologically, granulomatous inflammation is the clustering of epithelioid cells in a lymphoid background. ${ }^{1}$ Multinucleated foreign body or Langhans' giant cells and caseous necrosis may or may not be present. Granulomatous inflammation is not only a manifestation of tuberculosis but also a variety of diseases like leprosy, mycoses, sarcoidosis to mention only a few. ${ }^{2}$ Ziehl-Neelsen staining of the smears from the aspirates of granulomatous lesions is very helpful in establishing a tubercular aetiology.

\section{MATERIAL AND METHODS}

For the present study those patients were included who presented with an external swelling, which on cytological examination revealed.

- Typical granulomatous picture

- $\quad$ Plenty of necrosis and inflammatory cells (Without well formed epithelioid granulomas)-a typical granulomatous picture. 
In all the cases, aspiration was performed using $23 \mathrm{G}$ needle and $10 \mathrm{~mL}$ syringe. Air dried smears were made and stained by May-Grunwald-Giemsa stain and Ziehl-Neelsen stain respectively. Known positive smears were used with each batch of staining as positive controls; 10 cases served as negative controls. Cytomorphological diagnosis in these 10 cases were reactive lymph nodes $(\mathrm{n}=2)$, malignant tumour $(n=2)$, fibroadenoma breast $(n=2)$, colloid goitre $(n=2)$ and pleomorphic adenoma of parotid gland $(n=2)$.

Bacillary count reporting was done according to Revised National TB Control Programme (RNTCP). Bacterial load was graded from 0 to $3+$.

\section{RESULTS}

Out of a total of 1000 patients attending the cytology section of Pathology Department, Assam Medical College and Hospital, Dibrugarh, the cytologic aspirates of 100 patients showed granulomatous inflammation. When subsequently ZiehlNeelsen staining was done, then AFB positivity was seen only in tubercular lesions. In leprosy though smears were not positive with standard $\mathrm{ZN}$ staining, but by using $5 \% \mathrm{H}_{2} \mathrm{SO}_{4}$ as decolourizer the smear showed AFB positivity in one case. Out of 100 granulomatous lesions 89 were of tubercular origin, 4 cases of granulomatous thyroiditis, 2 cases were of sporotrichosis, 2 cases of leprosy and 1 case each of cat scratch disease, sarcoidosis and granulomatous mastitis. Most common site of involvement in tuberculosis was found to be lymph node (95.5\%), extranodal sites included breast (1.12\%), sternum (1.12\%) and parotid gland (2.24\%). Out of the 89 cases finally diagnosed as tuberculosis, $60(67.4 \%)$ cases showed epithelioid granuloma with necrosis, 14 (15.7\%) cases showed epithelioid granuloma without necrosis [Fig. I and Fig. II] and 15 (16.8\%) showed only necrosis without epithelioid granulomas (Table I). When major cytologic features were correlated individually for AFB positivity, it was found that $37(61.6 \%)$ cases of epithelioid granulomas with necrosis showed AFB positivity, 3 (21.4\%) cases of epithelioid granulomas without necrosis showed AFB positivity and 11 $(73.3 \%)$ cases of necrosis without epithelioid granulomas showed AFB positivity (Table II). AFB positivity hence was maximum in lesions showing large amounts of necrosis without epithelioid granulomas, $\mathrm{p}<0.001$ which is highly significant; $74.4 \%$ cases showed bacillary count of grade $1+$ followed by $21.5 \%$ cases with grade $2+$ and $3.9 \%$ cases with grade $3+$ bacillary count (Table III).

$2.7 \%$ cases of epithelioid granuloma with necrosis had bacillary count of grade $3+; 9 \%$ cases of necrosis without epithelioid granuloma had bacillary count of grade $3+$. Bacillary count in none of the cases of epithelioid granuloma without necrosis was of grade $3+$.

Smear of aspirates from tuberculous lesions showed presence of lymphocytes, neutrophils and giant cells. These cellular components were hence correlated with the major cytologic features. In smears of epithelioid granulomas with necrosis $34(56.6 \%)$ cases showed lymphocytes, 1 (1.6\%) case showed giant cells, $25 \quad(14.6 \%)$ cases showed polymorphonuclear cells (neutrophils). In smears of epithelioid granulomas without necrosis, 11 (78.5\%) cases showed lymphocytes, 1 (7.1\%) case showed giant cells, 5 (35.7\%) cases showed polymorphonuclear cells. In smear of necrosis without epithelioid granuloma, 8 (53.3\%) cases showed lymphocytes and $13(86.8 \%)$ cases showed polymorphonuclear cells. No giant cells seen in these smears. Lymphocytes and giant cells accompany epithelioid granuloma without necrosis and polymorphonuclear cells accompany necrosis without epithelioid granuloma. $\mathrm{p}<0.001$ which is very highly significant. AFB positivity was seen highest in cases with epithelioid granuloma with polymorphs (100\%) [Fig. III and Fig. IV] and in cases of necrosis with polymorphs $(85.7 \%)$. Thus polymorphs were associated with increased AFB positivity. Out of total 89 cases 28 (31.4\%) cases yielded a purulent aspirate, $48(53.9 \%)$ cases yielded a caseous or cheesy aspirate and $13(14.6 \%)$ cases yielded a blood mixed aspirate. So we see that majority of patients on aspiration yielded a cheesy aspirate. Majority of cases (38) of epithelioid granuloma with necrosis yielded a cheesy aspirate. Majority of cases (8) of epithelioid granuloma without necrosis yielded a cheesy aspirate. Majority of cases (13) of necrosis without epithelioid granuloma showed a purulent aspirate. When relation of nature of aspirate with AFB positivity was studied it was found that 24 cases of purulent aspirate $(85.7 \%)$ showed AFB positivity, 24 cases of cheesy aspirate $(50 \%)$ showed AFB positivity and 3 cases of blood mixed aspirate $(23.07 \%)$ showed AFB positivity. $\mathrm{P}<0.001$ which is very highly significant. Out of 89 cases finally diagnosed as tuberculosis, $74(83.1 \%)$ cases were diagnosed by cytomorphology alone and $86(96.6 \%)$ cases were diagnosed by cytomorphology with AFB staining. Hence, AFB staining is a very useful method to supplement cytological diagnosis of tubercular lesions.

\begin{tabular}{|c|c|c|}
\hline $\begin{array}{c}\text { Cytomorphologic } \\
\text { Features }\end{array}$ & Number & $\begin{array}{c}\text { Percentage } \\
\text { (\%) }\end{array}$ \\
\hline $\begin{array}{c}\text { Epithelioid granuloma } \\
\text { with necrosis }\end{array}$ & $60(89)$ & $67.4 \%$ \\
\hline $\begin{array}{c}\text { Epithelioid granuloma } \\
\text { without necrosis }\end{array}$ & $14(89)$ & $15.7 \%$ \\
\hline $\begin{array}{c}\text { Necrosis without } \\
\text { epithelioid granuloma }\end{array}$ & $15(89)$ & $16.8 \%$ \\
\hline \multicolumn{2}{|c|}{ Table I: Cytomorphology of Tuberculosis } \\
\hline
\end{tabular}

\begin{tabular}{|c|c|c|}
\hline Features & $\begin{array}{c}\text { AFB } \\
\text { Positivity }\end{array}$ & $\begin{array}{c}\text { Percentage } \\
\text { (\%) }\end{array}$ \\
\hline $\begin{array}{c}\text { Epithelioid granuloma } \\
\text { with necrosis }\end{array}$ & $37(60)$ & $61.6 \%$ \\
\hline $\begin{array}{c}\text { Epithelioid granuloma } \\
\text { without necrosis }\end{array}$ & $3(14)$ & $21.4 \%$ \\
\hline $\begin{array}{c}\text { Necrosis without } \\
\text { epithelioid granuloma }\end{array}$ & $11(15)$ & $73.3 \%$ \\
\hline \multicolumn{2}{|c|}{ p<0.001 } \\
\hline \multicolumn{2}{|c|}{ Table II: Correlation of Major Cytologic Features } \\
with AFB Positivity in Tuberculosis
\end{tabular}

\begin{tabular}{|c|c|c|c|c|}
\hline Major Cytologic Features & Scanty & $1+$ & $2+$ & $3+$ \\
\hline $\begin{array}{l}\text { Epithelioid granuloma } \\
\text { with necrosis }\end{array}$ & - & 30 & 6 & 1 \\
\hline $\begin{array}{l}\text { Epithelioid granuloma } \\
\text { without necrosis }\end{array}$ & - & 3 & - & - \\
\hline $\begin{array}{c}\text { Necrosis without } \\
\text { epithelioid granuloma }\end{array}$ & - & 5 & 5 & 1 \\
\hline Total & - & 38 & 11 & 2 \\
\hline \multicolumn{5}{|c|}{$\begin{array}{l}\text { Table III: Correlation of Major Cytologic } \\
\text { Features with Bacillary Count }\end{array}$} \\
\hline
\end{tabular}




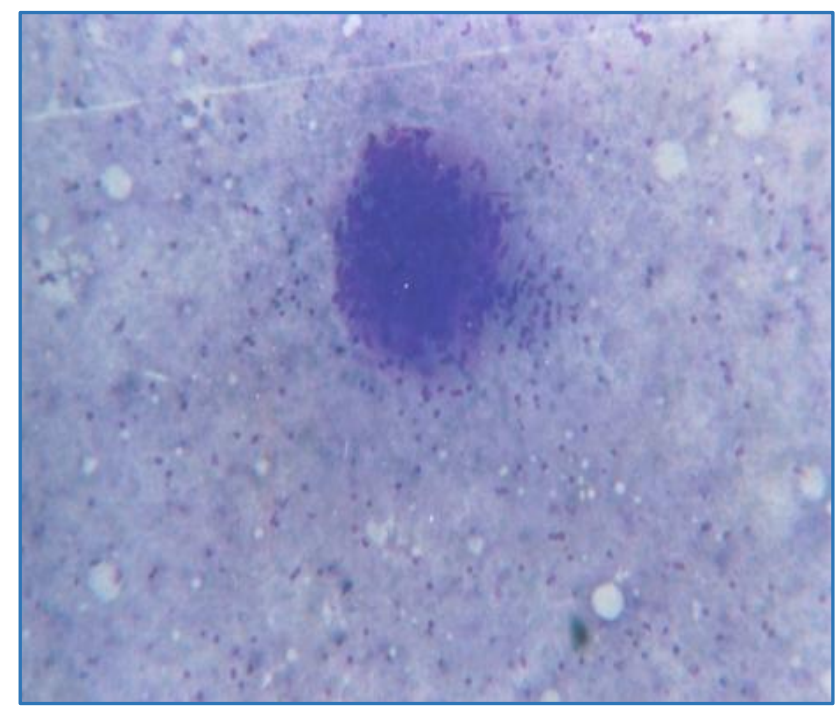

Fig. I: Microphotograph showing Epithelioid Granuloma (MGG Stain)

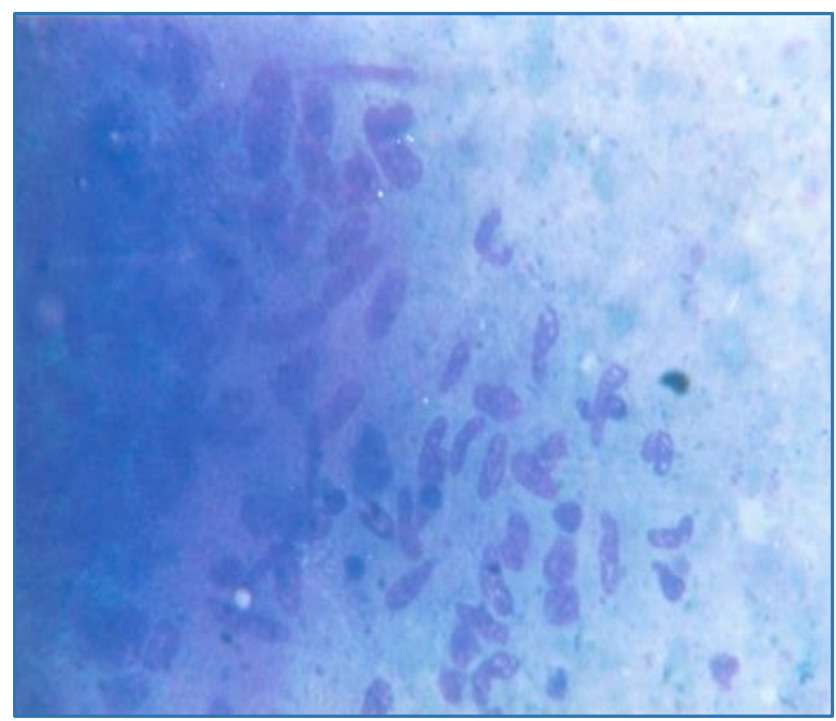

Fig. II: Microphotograph showing Epithelioid Granuloma (MGG Stain)

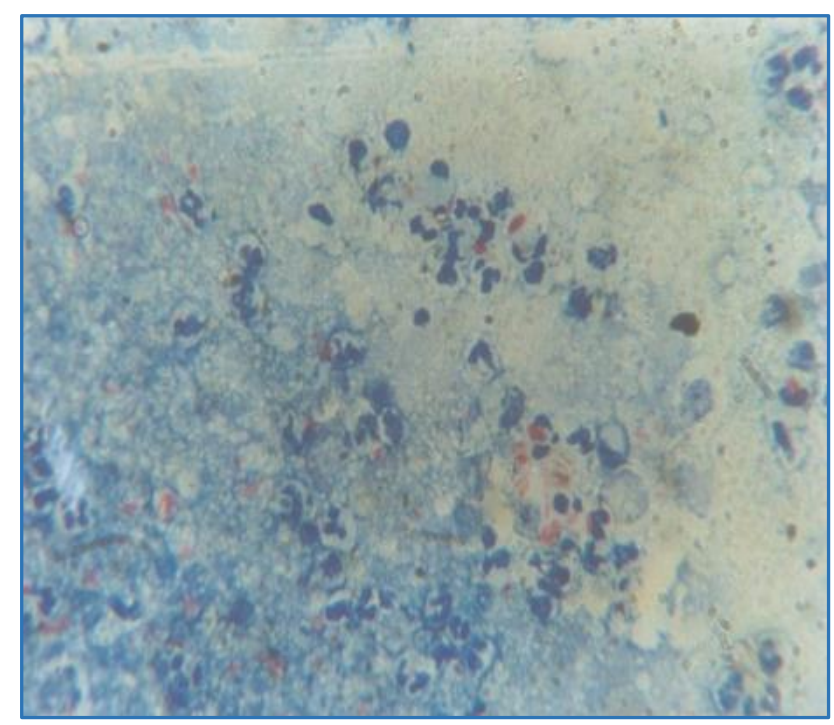

Fig. III: Microphotograph showing Acid-Fast Bacilli (Z/N Stain)

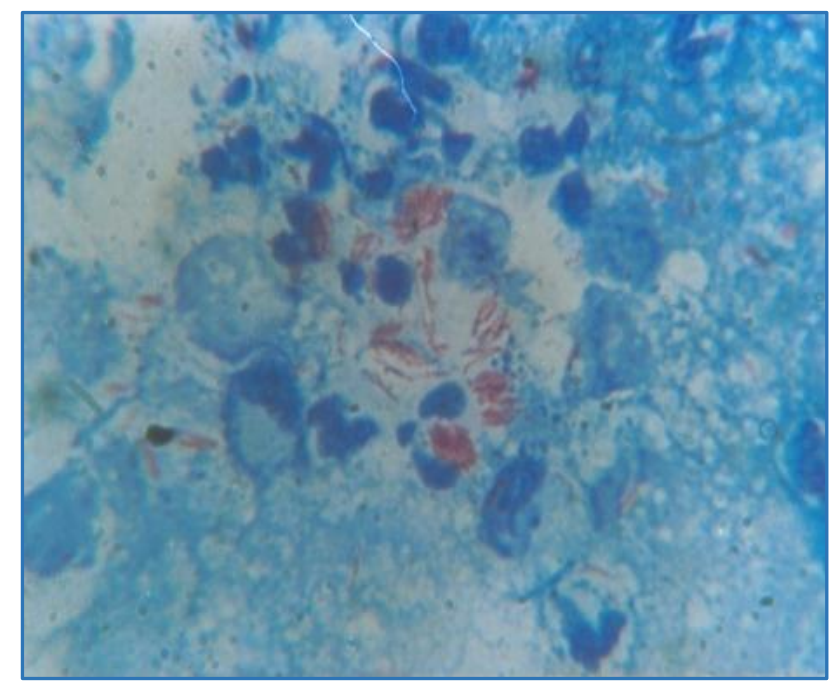

Fig. IV: Microphotograph showing AcidFast bacilli (Z/N Stain)

\section{DISCUSSION}

Granulomatous responses can be caused by several factors, the most common in India being the tubercle bacillus. The histological feature in these disorders may be quite typical so as to be diagnosed by an experienced pathologist, but in cases where atypical presentation is seen, help of other ancillary tests on special stains may be required.

The understanding of these granulomatous disorders is very important, as their incidence is high in India and early diagnosis and treatment can decrease morbidity and mortality load to a great extent. Though the histological appearance of the tissue is the final arbiter of diagnosis, the delay involved may at times affect the course of treatment.

Out of 1000 cases attending cytology outdoor, 100 cases turned out to be of granulomatous category. Majority of the cases $(89 \%)$ were of tubercular origin. The rest nontubercular lesions included 4 cases of granulomatous thyroiditis, 2 cases of sporotrichosis and leprosy each, 1 case of cat scratch disease, sarcoidosis and granulomatous mastitis each. AFB positivity was seen only in tubercular aspirates (by standard ZN method).

Out of 89 cases of tuberculosis, 51 cases (57.3\%) were AFB positive. No false positive results seen. Overall, AFB positivity in various series:

- $\quad$ Rajwanshi et al (1987). ${ }^{3} 40.6 \%$.

- $\quad$ N. Kumar et al (1998).4 33.5\%.

- Wondwossen Ergete et al (2000). 5 71.7\%.

- Present study $57.3 \%$.

In all the studies both nodal and extranodal sites were included, but the number of cases of respective sites are different which might be the cause of variation of AFB positivity.

In this study most of the tubercular patients presented with nodal swelling (95.52\%), which tallies with the finding of Bhattacharya et al.6 Extranodal sites comprised of breast (1.12\%), sternum (1.12\%) and parotid gland (2.24\%). Majority of the cases showed epithelioid granuloma with necrosis (67.4\%), which tallies with the findings of Rajwanshi et al (1987), Shameen Shariff et al (1991). ${ }^{7}$ and Wondwossen et al (2000). AFB positivity was maximally seen in necrosis without epithelioid granulomas $(73.3 \%)$, probably this is due to liquefaction of the necrotic foci which is associated with 
marked proliferation of tubercle bacilli. Epithelioid cells home some role in limiting the infections. This finding tallies with the finding of Rajwanshi et al (1987), M. S. Metre et al (1987), ${ }^{8} \mathrm{D}$. K. Das et al (1990), ${ }^{9}$ Bezabih M et al (2002). ${ }^{10}$

Lymphocytes (78.5\%) and giant cells (7.1\%) were maximally present in the epithelioid granulomas without necrosis. Polymorphonuclear cells (86.6\%) were mainly present in cases of necrosis without epithelioid granulomas; $\mathrm{p}<0.001$ which is very highly significant which tallies with the findings of D. K. Das et al (1990).

Depending on the presence of epithelioid cells, necrosis, lymphocytes, giant cells and polymorphonuclear cells, the 3 major cytologic types were further divided into 13 various subtypes. It was found that majority of the cases belonged to subtype containing epithelioid cells and necrosis (24.7\%). Second largest group belonged to subtype containing epithelioid cells with necrosis, lymphocytes and polymorphs (23.5\%). When all these subtypes were correlated with AFB positivity, it was seen that highest AFB positivity was seen in subtype containing epithelioid cells with polymorphs (100\%) and necrosis with polymorphs (85.7\%).

Das DK et al, 1990 found that maximal AFB positivity was seen in subtype containing epithelioid cells with necrosis, lymphocytes, polymorphs and giant cells (100\%). Second subtypes showing highest AFB positivity contained necrosis with polymorphs (80.8\%), which tallies with this study.

Majority of the cases of epithelioid granulomas with necrosis yielded a cheesy aspirate $(63.3 \%)$ and majority of the cases of necrosis without epithelioid granulomas yielded a purulent aspirate (86.6\%). These findings tally with the findings of M.S. Metre et al (1987) and Prasoon D (2000). ${ }^{11}$ $83.1 \%$ cases were diagnosed by cytomorphology and $96.6 \%$ cases were diagnosed by cytomorphology combined with AFB staining. This tallies with the findings of Rajwanshi et al (1987) and Wondwossen et al (2000).

So we see that AFB staining is of immense help in cases where classical features of tuberculosis are not seen because of high bacterial load. Unnecessary surgery can be avoided by providing a conclusive diagnosis of tuberculosis in absence of classical cytomorphological features and clinical parameters.

\section{CONCLUSION}

A variety of diseases may manifest as granulomatous inflammation in cytology, but the presence of acid-fast bacilli in smears would enable a tuberculous aetiology to be established. In this study out of 1000 cases analysed, 100 cases showed characteristics of granulomatous disorder. Out of these 100 cases, majority (89\%) were of tubercular origin. Most of the cases came with nodal swellings (87\%) and the rest with extranodal swellings (breast- $2 \%$, thyroid- $4 \%$, soft tissue- $4 \%$, sternum-1\%, parotid-2\%). Ziehl-Neelsen staining for acid-fast bacilli was found to be positive only in tubercular granulomas. All the non-tubercular granulomas were AFB negative. One case of lepromatous leprosy showed AFB positivity with modified Ziehl-Neelsen method (Using 5\% sulphuric acid as decolourising agent).

Tubercular lymphadenitis was the commonest mode of presentation. The cytomorphological features of tubercular lesions were divided into three major groups - epithelioid granulomas with necrosis (67.4\%), epithelioid granulomas without necrosis $(15.7 \%)$ and necrosis without epithelioid granulomas $(16.8 \%)$. The overall AFB positivity was $57.3 \%$.
AFB positivity in the three major groups was $61.6 \%, 21.4 \%$ (Least) and $73.3 \%$ (Highest) respectively ( $\mathrm{p}<0.001$, that is very highly significant). Cases with very high bacillary count (More than 10 AFB per oil immersion field) were associated with necrosis. Depending on the varying proportions of epithelioid cells, lymphocytes, necrosis, giant cells and polymorphonuclear cells in smears, the three major groups were divided into 13 subtypes. Though majority of the smears showed epithelioid cells and necrosis, but the AFB positivity was highest in cases where polymorphonuclear cells were present. Epithelioid cells and lymphocytes hence have some role in limiting the disease and necrosis and polymorphonuclear cells are associated with progression of the disease. Similarly, though in majority of the cases cheesy aspirates (53.9\%) were seen, but AFB positivity was highest in case with purulent aspirates $(85.7 \%)$. In cases where there is plenty of necrosis and polymorphonuclear cells infiltration, a misdiagnosis of tumour necrosis and suppurative inflammation may be done. Fortunately, in such cases AFB positivity is seen highest, so AFB staining is a must in such cases. When AFB positivity was combined with cytomorphology for cytodiagnosis of extrapulmonary tuberculosis, it was seen that confirmed diagnosis could be done in $96.6 \%$ cases. When only cytomorphology was taken in account, $83.1 \%$ cases could be diagnosed.

\section{TO CONCLUDE}

1. AFB staining is a very simple, cheap and reliable method to confirm a tubercular origin and to differentiate the tubercular granulomas from non-tubercular granulomas.

2. AFB staining provides a conclusive diagnosis of tuberculosis in the absence of classical cytomorphology, thereby avoiding unnecessary surgery in difficult cases.

3. AFB staining increases the diagnostic accuracy in cytodiagnosis of tubercular lesions.

\section{REFERENCES}

1. Orell SR, Sterrett GF, Walters MN, et al. Manual and atlas of fine needle aspiration cytology. Nils G Stormby, editor. An Imprint of Harcourt Publishers Limited. $3^{\text {rd }}$ edn. Publisher-Churchill Livingstone, Edinburg Ch 5, 2001:p 84.

2. Cotran RS, Kumar V, Collins T. Robbins pathologic basis of disease. A harcourt health sciences company. $6^{\text {th }}$ edn. Philadelphia Publisher-W.B. Saunders Company Cp 3, 2000:p 83.

3. Rajwanshi A, Bhambani S, Das DK. Fine needle aspiration cytology in diagnosis of tuberculosis. diagnostic cytopathology 1987;3(1):13-6.

4. Kumar N, Tiwari MC, Verma K. AFB staining in cytodiagnosis of tuberculosis without classical features: a comparison of Ziehl Neelsen and fluorescent methods. Cytopathology 1998;9(3):208-14.

5. Ergete W, Bekele A. Acid fast bacilli in aspiration smears form tuberculous patients. The Ethiopian Journal of Health development 2000;14(1):90-104.

6. Bhattacharya S, Raghuveer CV, Adhikari P. FNAC with diagnosis of tuberculosis-an eight years study at Mangalore. Indian J Med Sci 1998;52(11):498-506.

7. Shariff $S$, Thomas JA. Fine needle aspiration cytodiagnosis of clinically suspected tuberculosis in tissue enlargements. Acta Cytologica 1991;35(3):333-6. 
8. Metre MS, Jayaram G. Acid fast bacilli in aspiration smears from tuberculous lymph nodes. An analysis of 255 cases. Acta Cytol 1987;31(1):17-9.

9. Das DK, Part CS, Chachra KL, et al. Fine needle aspiration cytology diagnosis of tuberculous thyroiditis. A report of eight cases. Acta Cytol 1992;36(4):517-22.
10. Bezabih M, Marian DW, Selassie SG. Fine needle aspiration cytology of suspected tuberculous lymphadenitis (in Process citation). Cytopathology 2002;13(5):284-90.

11. Prasoon D. Acid-fast bacilli in fine needle aspiration smears from tuberculous lymph nodes. Where to look for them. Acta cytol 2000;44(3):297-300. 